\title{
CUANTIFICACIÓN DE LA RECARGA AL ACUÍFERO EN EL SECTOR INFERIOR DE LA CUENCA DEL RÍO CARCARAÑÁ
}

\section{QUANTIFICATION OF THE RECHARGE TO THE AQUIFER IN THE LOWER SECTOR OF THE CARCARAÑÁ RIVER BASIN}

\author{
Marcelo H. Polare ${ }^{(1)(*)}$ y Luis S. Vives ${ }^{(2)(3)}$ \\ ${ }^{(1)}$ Facultad de Ciencias Exactas, Ingeniería yAgrimensura.Universidad Nacional de Rosario. Rosario, Santa \\ Fe, Argentina. \\ ${ }^{(2)}$ Instituto de Hidrología de Llanuras. Universidad Nacional del Centro de la Provincia de Buenos Aires. \\ Azul, Buenos Aires, Argentina. \\ ${ }^{(3)}$ Consejo Nacional de Investigaciones Científicas y Técnicas. Buenos Aires, Argentina. \\ ${ }^{(*)}$ e-mail: mpolare@fceia.unr.edu.ar
}

\begin{abstract}
RESUMEN
En este trabajo se presenta el cálculo de la recarga al acuífero en el sector inferior de la cuenca del río Carcarañá, provincias de Córdoba y Santa Fe, Argentina. En primer instancia se definieron cinco zonas de recarga a partir de un profundo estudio edafológico de los suelos, y desarrollando de manera novedosa el empleo de la capacidad de uso de los mismos como una herramienta robusta a la hora de la delimitación y zonificación. En función de los datos meteorológicos recopilados, se dividió la zona de estudio en tres sectores representados cada uno por una localidad (Oliveros, Casilda y Marcos Juárez). En cada uno de estos sectores se cuantificó la recarga mediante balances hídricos seriados aplicando el método exponencial a paso diario. Para esto, y teniendo como datos de ingreso las variables agrohidrológicas de los suelos, precipitaciones y evapotranspiraciones potenciales diarias, se implementó una planilla de cálculo que brinda valores de recarga diarias, mensuales y anuales. Como resultadospara el período 1962-1966, la relación promedio recarga - precipitaciónpara la mejor zona de recarga varió de 16.5\% en Oliveros a 6.5\% en Marcos Juárez.
\end{abstract}

Palabras clave: mapa de recarga, capacidad de uso del suelo, balance hídrico seriado, cálculo de recarga.

\begin{abstract}
This paper presents the calculation of aquifer recharge in the lower sector of the Carcarañá river basin, provinces of Córdoba and Santa Fe, Argentina. In the first instance, five recharge zones were defined on the basis of an in-depth edaphological study of the soils, and the use of their capacity of use as a robust tool for delimitation and zoning was developed in a novel way. Based on the meteorological data collected, the study area was divided into three sectors, each represented by a locality (Oliveros, Casilda and Marcos Juárez). In each of these sectors, recharge was quantified by means of serial water balances applying the exponential method at a daily rate. For this purpose, and taking as input data the agro-hydrological variables of the soils, precipitation and potential daily evapotranspiration, a spreadsheet was implemented that provides daily, monthly and annual recharge values. As results for the period 1962-1966, the average recharge - precipitation ratio for the best recharge zone varied from 16.5\% in Oliveros to 6.5\% in Marcos Juárez.
\end{abstract}

Keywords: recharge map, land use capacity, serial water balance, recharge calculation. 


\section{INTRODUCCIÓN}

La cuenca inferior del río Carcarañá se extiende desde el sudeste de la provincia de Córdoba y ocupa la zona centro - sur de la provincia de Santa Fe. El río toma su nombre desde la confluencia del río Tercero y el sistema conformado por los ríos Cuarto y Saladillo, en la provincia de Córdoba, e ingresa en la provincia de Santa Fe en cercanías de la localidad de Cruz Alta. Antes de desembocar en el río Coronda, el río Carcarañá recorre la provincia de Santa Fe a lo ancho, recibiendo los aportes de los arroyos Tortugas, de las Mojarras, Leones y Cañada de Gómez.

La cuenca está enclavada en una zona agrícola ganadera por excelencia, donde en los últimos tiempos hubo una evolución desde la ganadería a una actividad agrícola predominante, siendo los cultivos principales: soja, maíz, trigo, sorgo y girasol. Más de 40 localidades se encuentran ligadas a la cuenca baja del río Carcarañá, las que, además de la agricultura y la ganadería, tienen su sostén en diversos emprendimientos comerciales e industriales, en donde la provisión de agua de calidad adquiere un carácter importante para el sostén de la población.

Si bien las localidades ubicadas el este de la provincia de Santa Fe captan agua potable de los cursos de agua superficiales, la problemática vinculada a la calidad y cantidad del agua disponible se manifiesta en el oeste de la provincia, fundamentalmente en lo que hace a la concentración de arsénico, que llega a alcanzar más de treinta veces lo recomendado por la Organización Mundial de la Salud para las personas. Pero también es para prestar mucha atención lo concerniente a la presencia de flúor, donde en la zona de estudio promedia el doble de lo recomendado por dicha organización. Salvo el abastecimiento de agua potable a las escasas localidades de la zona de estudio que se encuentran conectadas a los acueductos construidos, las aguas subterráneas constituyen la única fuente de suministro disponible, a través de captación mediante pozos de bombeo y posterior tratamiento mediante diversos métodos, como el de ósmosis inversa en localidades, o bien consumo directo para las numerosas estancias que se encuentran en dicha zona.

La gran mayoría de los pozos de captación se encuentran ubicados en los acuíferos que posee el paquete sedimentario cuaternario de la llanura pampeana (lo que informalmente se denomina: Sedimentos Pampeanos o Formación Pampeana) y en menor proporción en los localizados en las arenas que infrayacen a los Sedimentos Pampeanos. De los acuíferos citados, los pozos de captación se ubican en aquellos acuíferos que, fundamentalmente, provean agua de razonable calidad, ya que existen otros en donde las aguas no son aptas para el consumo, y con variaciones a nivel local dentro de la misma cuenca.

Por lo tanto, con la idea de implementar en un futuro cercano, un plan robusto de gestión del uso sustentable del agua subterránea apoyado con el empleo de un modelo numérico de flujo de agua subterránea, se requirió conocer en detalle los mecanismos para determinar la infiltración eficaz de este sistema acuífero de la cuenca inferior del río Carcarañá, que para este caso se asumió como la recarga al acuífero. Esto se realizó en el período 1962-1966 previo al inicio de los estudios y de esta forma comenzar con un sistema acuífero en equilibrio. La metodología para el cálculo de la recarga de este trabajo podrá ser extensiva en estudios para períodos posteriores hasta la actualidad.

\section{METODOLOGÍA}

El trabajo se desarrolló en dos etapas: la primera consistió en definir las distintas zonas de recarga de la zona de estudio, teniendo en cuenta las características físicas y químicas de los distintos tipos de suelos existentes en el área, sus texturas, la topografía y la intensidad de los procesos erosivos que los afectan. Estos factores son considerados de las Cartas de Suelos, utilizando como herramienta innovadora el empleo de las respectivas capacidades de uso de los suelos, y en particular de aquellos involucrados en la zona de estudio. Las zonas de recarga están constituidas por unidades cartográficas de suelos en función de los condicionantes que presentan para el escurrimiento superficial y el drenaje interno.

La segunda etapa fue cuantificar la recarga. Para ello se desarrollaron Balances Hídricos Seriados (BHS) aplicando el método exponencial a paso diario utilizando el procedimiento de Thornthwaite y Mather -TM- (1957). Este método se combinó con la modificación propuesta por Scozzafava y Tallini (2001), empleando el método del número de curva (CN) del Servicio de Conservación de Suelos del Departamento de Agricultura de Estados Unidos 
(USDA-SCS), actualmente Servicio de Conservación de Recursos Naturales (NRCS), para el cálculo del escurrimiento superficial provocado por un evento aislado, y que tiene en cuenta el tipo de suelo, el uso del mismo, la pendiente del terreno y la condición de humedad del suelo previa al evento.

Particularmente, Scozzafava y Tallini (2001) plantean a través del método del $\mathrm{CN}$ calcular primero el escurrimiento superficial (Q) y luego restar este valor a la lluvia total del evento (P), obteniendo una lluvia ficticia $\mathrm{P}_{\mathrm{f}}=\mathrm{P}-\mathrm{Q}$, y a la que se le aplican las ecuaciones correspondientes al balance hídrico. De esta manera, los excedentes calculados corresponden a la infiltración neta.

Para el cálculo de los BHS se tienen como datos las precipitaciones y evapotranspiraciones potenciales diarias en el período de estudio.

Con respecto a éstas últimas, el concepto de evapotranspiración potencial (ETP) fue introducido independientemente por Penman (1948) y Thornthwaite (1948), definiendo a la ETP como la máxima evaporación posible en un tiempo dado, cuando el suelo se encuentra en su contenido óptimo de humedad, sin limitante en el suministro hídrico y cubierto totalmente con un cultivo verde de baja altura, con un albedo entre 0.22 y 0.25 . En dicha definición la tasa de evapotranspiración no está relacionada a un cultivo específico.

Por este motivo se introdujo el concepto de evapotranspiración de la superficie de referencia, denominada evapotranspiración del cultivo de referencia o evapotranspiración de referencia $\left(\mathrm{ET}_{\mathrm{O}}\right)$, definiendo (Allen et al., 2006) dicho cultivo como “...un cultivo hipotético con una altura asumida de $0.12 \mathrm{~m}$, con una resistencia de la superficie de 70

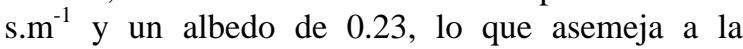
evaporación que ocurre en una superficie extensa de grama verde de altura uniforme, creciendo activamente y bien regada” (p. xiii).

El concepto de una superficie de referencia fue introducido con el fin de evitar la necesidad de definir los parámetros únicos de evapotranspiración para cada cultivo y etapa de crecimiento. Los valores de evapotranspiración de los diferentes cultivos se relacionan con la $\mathrm{ET}_{\mathrm{O}}$ por medio de los coeficientes de cultivo (Allen et al., 2006).

De los diversos métodos existentes para el cálculo de la $\mathrm{ET}_{\mathrm{O}}$, y tras una reunión de expertos en 1990, se recomienda adoptar para su cálculo el método combinado de Penman-Monteith de la Organización de las Naciones Unidas para la Agricultura y la Alimentación (FAO) según la publicación FAO-56 (método FAO-56 P-M), ya que los valores obtenidos por dicho método son más consistentes con datos reales del uso de agua de diversos cultivos en todas las regiones y climas (Allen et al., 2006). La ecuación utiliza datos climáticos de radiación solar, temperatura del aire, humedad y velocidad del viento (Ecuación 1):

$$
E T_{o}=\frac{0.408 \Delta\left(\mathrm{R}_{\mathrm{n}}-G\right)+\gamma \frac{900}{T+273} u_{2}\left(\mathrm{e}_{\mathrm{s}}-e_{a}\right)}{\Delta+\gamma\left(1+0.34 u_{2}\right)}
$$

donde $\operatorname{ET}_{\mathrm{O}}\left(\mathrm{mm} . \mathrm{d}^{-1}\right)$ es la evapotranspiración de referencia, $R_{n}\left(M J \cdot m^{-2} \cdot d^{-1}\right)$ es la radiación neta en la superficie del cultivo, $\mathrm{G}\left(\mathrm{MJ} \cdot \mathrm{m}^{-2} \cdot \mathrm{d}^{-1}\right)$ es el flujo del calor del suelo, $\mathrm{T}\left({ }^{\circ} \mathrm{C}\right)$ es la temperatura media del aire a $2 \mathrm{~m}$ de altura, $\mathrm{u}_{2}\left(\mathrm{~m} . \mathrm{s}^{-1}\right)$ es la velocidad del viento a $2 \mathrm{~m}$ sobre la superficie, $\mathrm{e}_{\mathrm{s}}(\mathrm{kPa})$ es la presión de vapor de saturación, $\mathrm{e}_{\mathrm{a}}(\mathrm{kPa})$ es la presión real de vapor, $\Delta\left(\mathrm{kPa} .{ }^{\circ} \mathrm{C}^{-1}\right)$ es la pendiente de la curva de presión de vapor y $\gamma\left(\mathrm{kPa} .{ }^{\circ} \mathrm{C}^{-1}\right)$ es la constante psicrométrica. De esta forma $e_{s}-e_{a}(k P a)$ es el déficit de presión de vapor.

Finalmente, y para efectuar los estudios de balance hídrico, se desarrolló e implementó una planilla de cálculo que realiza un BHS aplicando el método exponencial a paso diario utilizando el procedimiento de TM, combinándolo con la modificación propuesta por Scozzafava y Tallini (2001) que emplea el método del número de curva (CN).

La planilla incorpora un módulo inicial destinado a la determinación de la Capacidad de Agua Disponible (CAD) para el cultivo y que es la cantidad de agua que puede retener el suelo entre los valores de Capacidad de Campo (CC) y de Punto de Marchitez Permanente (PMP). La CAD es el agua que dispone el cultivo para su crecimiento.

Para ello se implementó un modelo de suelo edáfico estructurado en cuatro horizontes, caracterizados cada uno por los datos de espesor y las humedades correspondientes a la CC y al PMP expresadas en volumen (Figura 1).

Además, se necesita ingresar el valor de la profundidad radicular efectiva del cultivo. La planilla calcula automáticamente, en función de los 
espesores de los horizontes cargados, las profundidades radiculares parciales correspondientes al modelo de suelo considerado.

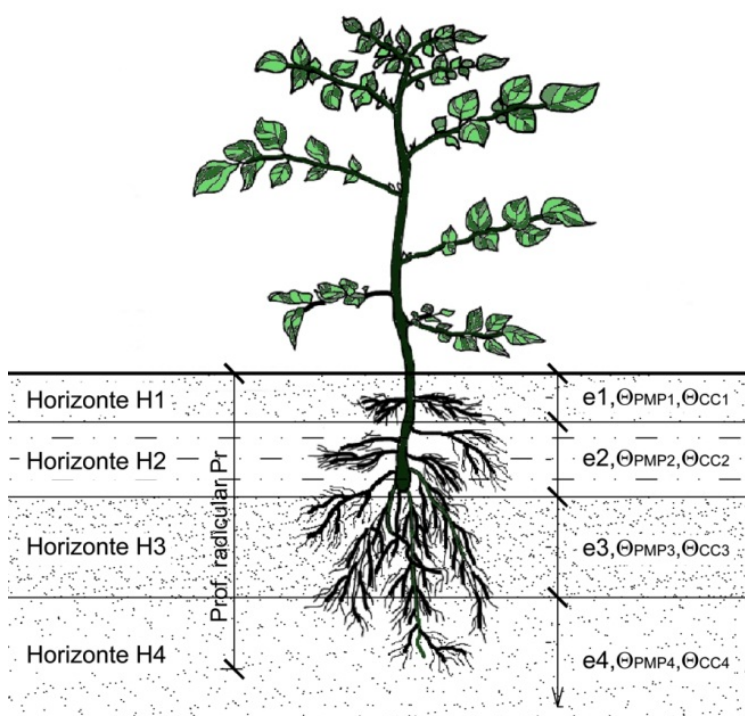

Figura 1. Modelo de suelo implementado en el programa y datos requeridos para cada horizonte. Fuente: Polare (2019).

La CAD se calcula mediante la Ecuación (2):

$\mathrm{CAD}=\sum_{\mathrm{i}=1}^{4}\left(\theta_{\mathrm{CC}_{\mathrm{i}}}-\theta_{\mathrm{PMP}_{\mathrm{i}}}\right) \mathrm{Pr}_{\mathrm{i}}$

donde CAD (mm) es la capacidad de agua disponible, $\theta_{\mathrm{CCi}}\left(\mathrm{m} . \mathrm{m}^{-1}\right)$ es la humedad de la capacidad de campo de cada horizonte, $\theta_{\mathrm{PMPi}}\left(\mathrm{m} . \mathrm{m}^{-1}\right)$ humedad del punto de marchitez permanente de cada horizonte y $\operatorname{Pr}_{\mathrm{i}}(\mathrm{mm})$ es la profundidad radicular efectiva en cada horizonte.

Los datos de humedades de CC y de PMP de cada horizonte fueron calculados previamente mediante funciones de pedotransferencia incluidas en el programa SOILPAR (Acutis y Donatelli, 2003). Este programa permite determinar las propiedades agrohidrológicas de los suelos, previo ingreso de datos provenientes de las descripciones analíticas de series de suelos que se encuentran en las Cartas de Suelos de INTA. Dichos valores calculados se contrastaron posteriormente con datos brindados por la bibliografía existente, como Rawls et al. (1982).

Luego se ingresan en la planilla de cálculo los datos relacionados al método del $\mathrm{CN}$, como ser el número de curva $\mathrm{CN}_{\text {II }}$ y el coeficiente de abstracción inicial $\lambda$. El $\mathrm{CN}_{\mathrm{II}}$ se obtiene de tablas en función del Grupo Hidrológico de Suelo (GHS), uso y cobertura del suelo, condición previa de humedad media o promedio y $\lambda=0.20$. La planilla ofrece la posibilidad de elegir entre dos valores de $\lambda(0.20$ o $0.05)$, ya que para simulaciones continuas puede llegar a ser más apropiado, incrementando el escurrimiento directo para precipitaciones pequeñas (Westenbroek et al., 2010; Woodward et al., 2003). Si se elige $\lambda=0.05$, la planilla recalcula automáticamente el valor de $\mathrm{CN}_{\mathrm{II}}$ (Hawkins et al., 2009), ya que éste corresponde a un valor de $\lambda=$ 0.20 , como se citó anteriormente.

Para la elección de los números de curva correspondientes a condiciones de suelo seco y húmedo en función de la condición de humedad antecedente $\left(\mathrm{CN}_{\mathrm{I}}\right.$ y $\mathrm{CN}_{\mathrm{III}}$, respectivamente), se adoptó el criterio de la precipitación de los 5 días previos al evento considerado, adoptando los valores límites del método original.

Para iniciar el BHS se necesita cargar en la planilla de cálculo el almacenamiento inicial al principio del período de estudio.

Como se citó anteriormente, al trabajar con la lluvia ficticia $\mathrm{P}_{\mathrm{f}}$ los excedentes determinados por el balance hídrico constituyen las recargas a considerar para el acuífero. La planilla brinda los valores diarios de recarga, como así también los valores mensuales y anuales.

\section{ÁREA DE ESTUDIO}

El área de estudio comprende parte de las provincias de Santa Fe y Córdoba y abarca una superficie de $18000 \mathrm{~km}^{2}$. Se encuentra ubicada en plena Llanura Pampeana, comprendiendo la cuenca inferior del río Carcarañá (Figura 2). Presenta un paisaje con evidentes rasgos tectónicos y una morfología en la que se destaca la participación hídrica y eólica entre los procesos geomórficos de superficie, con un desnivel máximo de la superficie topográfica cercano a los $120 \mathrm{~m}$. El 57\% del área de estudio corresponde a la cuenca baja del río Carcarañá, y el resto a cuencas de cursos contiguas que no aportan al mismo.

\section{Aspectos climáticos de interés}

De acuerdo a la clasificación climática de Köppen, el clima de la zona de estudio es Cfa (subtropical húmedo), con veranos lluviosos y cálidos, sin 
estación seca (Kottek et al., 2006; Rubel y Kottek, 2010; Rohli y Vega, 2015).

Las precipitaciones medias anuales para el período 1921-2000 en la zona de estudio, llegan en la región oriental a un máximo de alrededor de $1000 \mathrm{~mm}$, disminuyendo hacia el oeste alcanzando valores de
$900 \mathrm{~mm}$. Las precipitaciones semestrales siguen la misma tendencia. En el semestre cálido (octubre a marzo), las precipitaciones varían de $750 \mathrm{~mm}$ en el sector este y disminuyen a unos $650 \mathrm{~mm}$ en el sector oeste, mientras que en el semestre frío (abril a setiembre), varían de $350 \mathrm{~mm}$ a $250 \mathrm{~mm}$ (Bianchi y Cravero, 2010; Cravero et al., 2017).

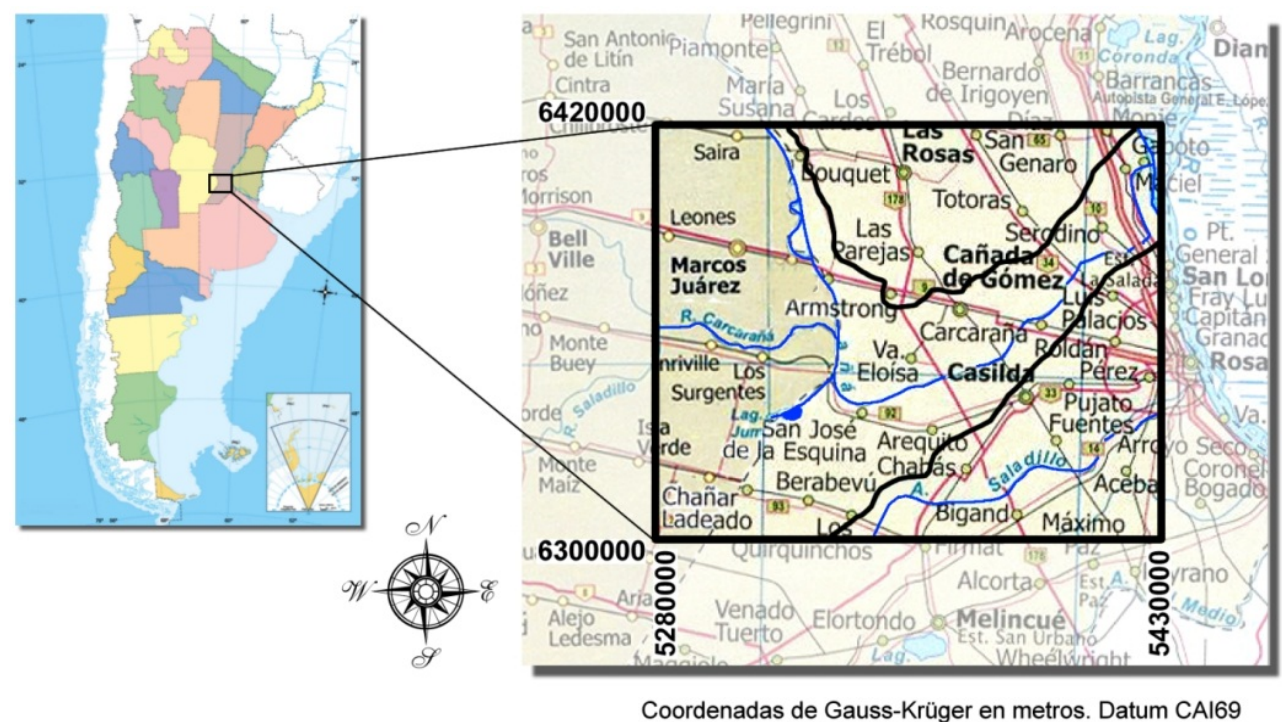

Figura 2. Área de estudio con los límites de la cuenca inferior del río Carcarañá. Fuente: Basada en Polare (2019).

A través de información pluviométrica recopilada en diversas estaciones de la provincia de Santa Fe (Rafaela, Oliveros, La Silesia, Marcos Juárez y Zavalla) entre 1971 y 2000, Venencio (2007) manifiesta que el máximo mensual de precipitación se produce al final del verano y principios de otoño (marzo, abril), mientras que el mínimo en invierno (junio-agosto). La concentración pluvial es desde octubre a marzo, y en algunos casos abril, cuando cae más del 70\% de la precipitación anual, mientras que en la estación seca (restodel año) se produce solamente un 30\%, y menos aún del total anual. Aun así, dicha región tiene lluvias todo el año. En la llanura cordobesa el $82 \%$ de las lluvias se concentran en primavera-verano y sólo el $18 \%$ en otoño-invierno, de acuerdo a registros de precipitación que corresponden a series de 30 a 76 años (Blarasin et al., 2000).

En cuanto a las temperaturas, la zona de estudio presenta variación de la temperatura media anual, como así también una variabilidad térmica media mensual en el mes más cálido (enero) y en el más frío (julio), respectivamente. Para el período 19212000, la temperatura media anual promedio para la zona de estudio es cercana a los $18^{\circ} \mathrm{C}$, y mientras en enero la temperatura media mensual oscila entre $25^{\circ} \mathrm{C}$ y $26{ }^{\circ} \mathrm{C}$, en julio varía entre $10^{\circ} \mathrm{C}$ y 11 ${ }^{\circ} \mathrm{C}$, aproximadamente.

Refiriéndonos al período de estudio 1962-1966, la temperatura media anual promedio ronda $\operatorname{los} 17^{\circ} \mathrm{C}$. La temperatura media mensual en enero es de alrededor de $24{ }^{\circ} \mathrm{C}$ y en julio de $11{ }^{\circ} \mathrm{C}$. Las precipitaciones medias anuales varían desde $930 \mathrm{~mm}$ en el sector este hasta los $720 \mathrm{~mm}$ en el sector oeste.

Se muestra en la Figura 3 las precipitaciones medias mensuales en Oliveros y Marcos Juárez, ambas cercanas a los límites este y oeste de la zona de estudio, respectivamente. 


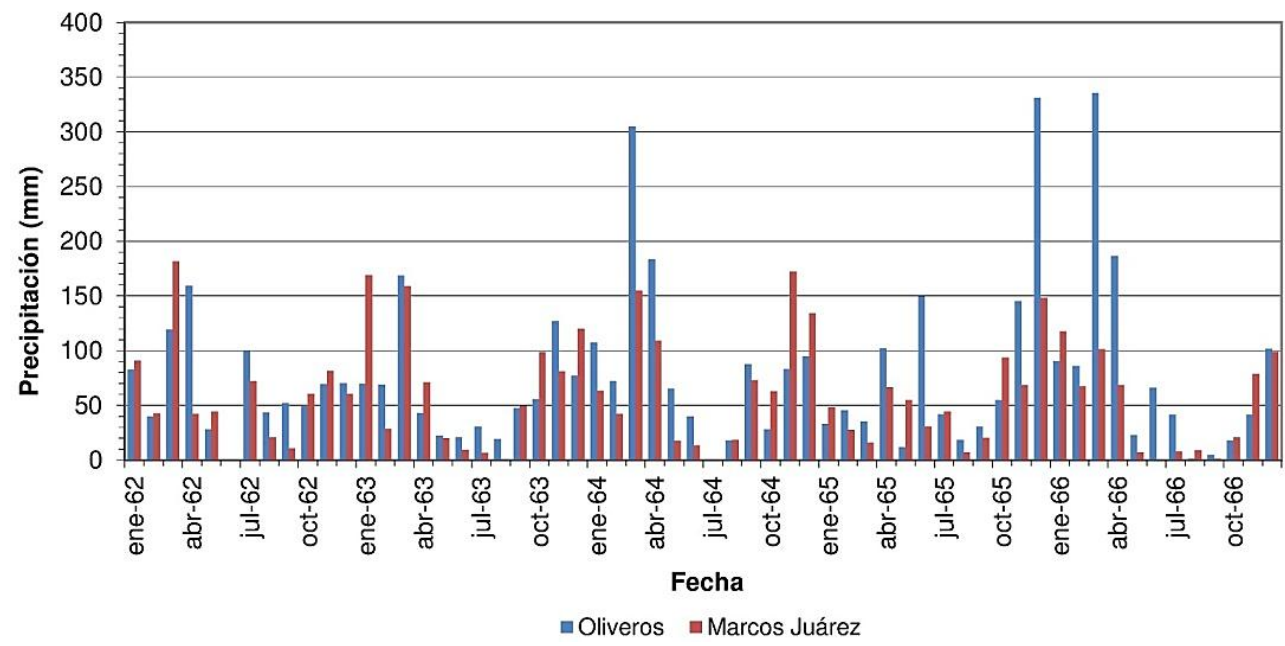

Figura 3. Precipitaciones medias mensuales en Oliveros y Marcos Juárez (1962-1966).

\section{Edafología}

Para la descripción y mapeo de los suelos que componen el área de estudio se tuvo como base la información en escala 1:500000 de la plataforma GeoINTA (un sistema para consulta de mapas, imágenes y bases de datos georreferenciadas de proyectos y programas del INTA - GeoINTA, 2013), el Mapa de Suelos de la provincia de Santa Fe (INTA - MAG, 1981), y el Atlas de Suelos de la República Argentina (INTA, 1990; INTA-Aeroterra SA, 1995).

En la Figura 4 se observan las unidades cartográficas de los suelos presentes en la zona de estudio, y cuyas leyendas están compuestas por cuatro partes que describen los nombres del suelo a nivel de Orden, Gran Grupo, Subgrupo y número de unidad cartográfica.

A continuación se describen brevemente las principales unidades cartográficas de suelos presentes en la zona.

La unidad MItc-1 ocupa cerca del $40 \%$ de la superficie de la zona de estudio y comprende planicies altas, bien drenadas y suavemente onduladas con una red de drenaje bien definida. Esta unidad está compuesta por Argiudoles típicos con una gran aptitud para la agricultura. Estos suelos presentan un horizonte B2t con mayor porcentaje de arcilla que dificulta la normal infiltración del agua de lluvia.

La unidad MItc-40 comprende una zona de transición de planos altos a planos bajos, ubicada al este del Bloque de San Guillermo y al este de la Falla El Trébol, considerando a éstas como referencias geológicas. La componen una asociación de Argiudoles típicos en las partes más altas y mejor drenadas del relieve, Argiudoles ácuicos en las partes intermedias y Argialboles típicos en las depresiones, donde el drenaje es sensiblemente inferior al de las anteriores disposiciones del paisaje.Las limitaciones de la unidad son la permeabilidad lenta en los Argiudoles ácuicos y el drenaje imperfecto en los Argialboles típicos.

La unidad MItc-6 corresponde a planicies altas muy extendidas y bien drenadas superficialmente. La planicie se presenta interrumpida por ejes de drenaje, o cauces de escurrimiento temporario, de orientación OSO-ENE dispuestos en forma paralela, compuestos por una sucesión de cubetas pequeñas que se interconectan en periodos de lluvia de cierta magnitud, drenando normalmente los sectores.La unidad está compuesta por una asociación de Argiudoles típicos en los sectores bien drenados, de lomas planas extendidas y Argiudoles ácuicos en los sectores deprimidos del paisaje, teniendo éstos como limitaciones la menor permeabilidad y drenaje.

La unidad MIve-1 tiene su desarrollo en un paisaje suavemente ondulado con lomas planas y extendidas, y moderadamente bien drenado. Está compuesta por Argiudoles típicos y Argiudoles vérticos. Comprende el área SE de la cuenca del Carcarañá y extendiéndose fuera de ella en el departamento San Lorenzo. Por el elevado contenido de materiales finos, estos suelos presentan problemas de permeabilidad, y en épocas de lluvias excesivas, los cultivos pueden sufrir asfixia por esa causa. 


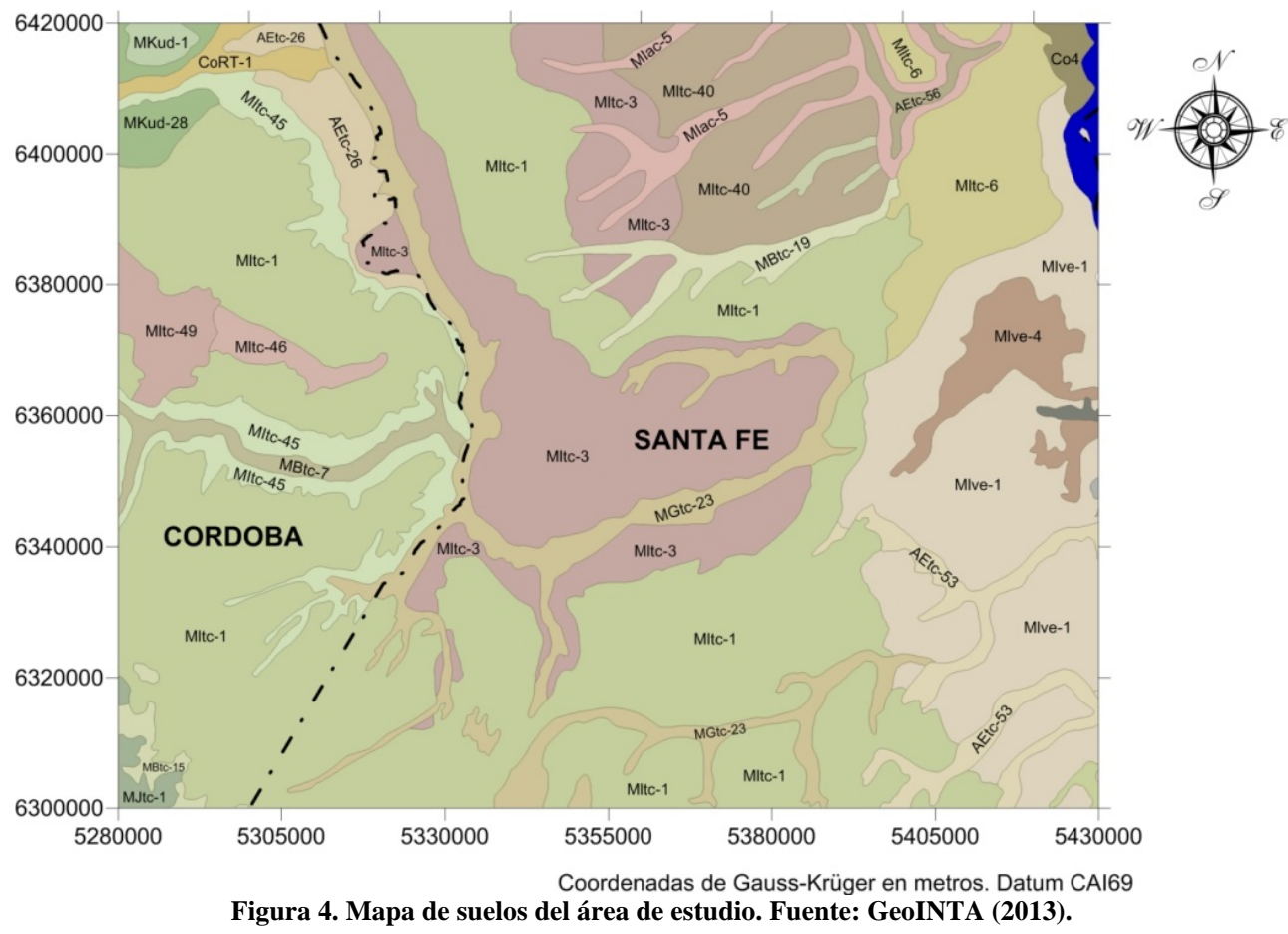

La unidad MIve-4 ocupa el centro del departamento San Lorenzo en un paisaje muy suavemente ondulado con lomas planas extendidas de relieve normal-subnormal y moderadamente bien drenadas, interrumpidas por planos bajos de relieve subnormal cóncavo, aledaños a vías de escurrimiento permanentes de lento drenaje. Se compone de una asociación de Argiudoles vérticos en los sectores de lomas y Natracualfes típicos en los planos bajos extendidos. La limitante de los Argiudoles vérticos es la permeabilidad lenta derivada del alto contenido de arcilla del horizonte $\mathrm{Bt}$, haciéndolos relativamente impermeables en períodos lluviosos, mientras que las limitaciones de los Natracualfes típicos es la sodicidad debida a su ubicación.

La unidad MItc-3 está compuesta por Argiudoles típicos presentando erosión hídrica actual. Ocupa altos suavemente ondulados y planos extendidos, áreas bien drenadas, con pendientes de hasta $2 \%$ ubicadas a ambas márgenes de los cauces principales (río Carcarañá y arroyo Cañada de Gómez). Ello contribuye a que los suelos sean susceptibles a la erosión hídrica ligera o moderada no solo por la pendiente natural del terreno sino por el mal manejo de estos suelos. Dichos suelos forman el extremo sur del Bloque Elevado de San Guillermo, y particularmente se desarrollan en las pendientes laterales del valle del río Carcarañá y fondos de valles tributarios y en el talud asociado a la Falla El Trébol.

La unidad MItc-45 ocupa parte de las pendientes laterales del valle del río Carcarañá en la provincia de Córdoba, y en las pendientes vinculadas a las cañadas de San Antonio, Santa Lucía y Las Totoras, como así también a los arroyos Tortugas y Leones. Está conformada por Argiudoles típicos ubicados en zonas de media loma y con limitaciones debidas a erosión hídrica actual, y Natracualfes típicos localizados en pies de pendiente y con limitaciones debidas a erosión hídrica actual y sodicidad.

Las restantes unidades (MGtc-23, MBtc-7, MBtc-19, AEtc-26, AEtc-53, AEtc-56, MIac-5, CoRT-1 y Co4) ocupan aproximadamente el 15\% de la zona de estudio, y corresponden a planos bajos extendidos y aledaños tanto a vías de escurrimiento de cauce elaborado como a las que no poseen una dirección definida. Se pueden encontrar en dichas unidades complejos de Natracuoles típicos, Natracualfes típicos, Argiudoles ácuicos, Natralboles típicos, Argialboles típicos, como así también complejos indiferenciados. Las limitaciones principales de los suelos están dadas por su imperfecto drenaje, susceptibilidad a inundación o anegamiento, pobre permeabilidad, lento a muy lento escurrimiento del exceso de agua, sodicidad y salinidad. 


\section{MAPA DE ZONAS DE RECARGA}

El mapa de zonas de recarga se confeccionó a partir de un mosaico aerofotográfico compuesto por 49 fotocartas de suelos en escala 1:50000, digitalizadas y georreferenciadas en proyección Gauss-Krüger faja 5 Datum CAI69. Además, se tomó como base la información brindada por las Cartas de Suelos de INTA (INTA, 1974-1988), como así también las correcciones de las mismas llevadas a cabo por dicho instituto (Tosolini -INTA-, com. pers.).

Se distinguieron en el área de estudio cinco zonas, atendiendo a los condicionantes presentes en las unidades cartográficas de suelos que las integran y que están íntimamente ligados al escurrimiento superficial y el drenaje interno.En la Tabla 1 se presenta un resumen de las características más relevantes de cada una de las zonas de recarga.

Los límites de cada zona de recarga se efectuaron a través de un proceso de vectorización mediante un programa de soporte SIG.

En la Figura 5 se muestra un modelo digital de elevaciones del área de estudio superpuesto con el mapa de zonas de recarga. En dicha figura puede observarse claramente la Zona 2 asociada a las mayores pendientes del terreno, generados por deformación tectónica o por acción fluvial.

Tabla 1. Características de las zonas de recarga.

\begin{tabular}{|c|c|c|c|c|c|}
\hline Zona & Tipo de suelo & Textura & $\begin{array}{c}\text { Topografía y/o } \\
\text { erosividad }\end{array}$ & $\begin{array}{c}\text { Drenaje, } \\
\text { salinidad/alcalinidad }\end{array}$ & $\begin{array}{l}\text { Capacidades } \\
\text { de uso } \\
\end{array}$ \\
\hline 1 & $\begin{array}{l}\text { Argiudoles típicos, } \\
\text { con una baja } \\
\text { proporción en el total } \\
\text { de Argiudoles } \\
\text { ácuicos y Argiudoles } \\
\text { vérticos }\end{array}$ & $\begin{array}{l}\text { Franco limosa } \\
\text { con un horizonte } \\
\text { de textura franco } \\
\text { arcillo limosa } \\
\text { intercalado }\end{array}$ & $\begin{array}{l}\text { Relieves llanos a } \\
\text { suavemente } \\
\text { ondulados y con nula } \\
\text { a ligera erosión }\end{array}$ & $\begin{array}{l}\text { Suelos profundos, } \\
\text { moderadamente bien } \\
\text { drenados a bien } \\
\text { drenados }\end{array}$ & I-1, I-1/2 y I-2 \\
\hline 2 & $\begin{array}{l}\text { Argiudoles típicos, } \\
\text { con una baja } \\
\text { proporción de } \\
\text { Argiudoles ácuicos y } \\
\text { suelos con alto } \\
\text { contenido de Sodio } \\
\text { y/o Sales Solubles } \\
\text { (Nátricos) }\end{array}$ & $\begin{array}{l}\text { Franco limosa } \\
\text { con un horizonte } \\
\text { de textura franco } \\
\text { arcillo limosa } \\
\text { intercalado }\end{array}$ & $\begin{array}{c}\text { Relieves con } \\
\text { pendientes suaves a } \\
\text { moderadamente } \\
\text { pronunciadas, con } \\
\text { erosión laminar y en } \\
\text { surcos moderada a } \\
\text { severa }\end{array}$ & $\begin{array}{c}\text { Drenaje restringido por } \\
\text { ligera a moderada } \\
\text { salinidad y/o } \\
\text { alcalinidad }\end{array}$ & $\begin{array}{l}\text { IIe, IIs, IIIe y } \\
\text { IIIes }\end{array}$ \\
\hline 3 & $\begin{array}{l}\text { Argiudoles típicos y } \\
\text { Argiudoles ácuicos, } \\
\text { y con presencia de } \\
\text { Argialboles y suelos } \\
\text { con alto contenido de } \\
\text { Sodio y/o Sales } \\
\text { Solubles (Nátricos) }\end{array}$ & $\begin{array}{l}\text { Franco limosa } \\
\text { con interc. de } \\
\text { horizontes de } \\
\text { textura franco } \\
\text { arcillo limosa y } \\
\text { arcillo limosa }\end{array}$ & $\begin{array}{l}\text { Suelos de relieve } \\
\text { llano, con pendientes } \\
\text { largas y gradientes } \\
\text { bajos, en general, } \\
\text { como así también } \\
\text { sectores cóncavos } \\
\text { alargados que reciben } \\
\text { excesos de agua } \\
\text { provenientes de los } \\
\text { sectores contiguos } \\
\text { más elevados. Nula a } \\
\text { ligera erosión }\end{array}$ & $\begin{array}{c}\text { Drenaje interno } \\
\text { imperfecto a pobre; en } \\
\text { algunos casos se } \\
\text { presenta una ligera a } \\
\text { moderada salinidad y/o } \\
\text { alcalinidad }\end{array}$ & $\begin{array}{l}\text { IIw, IIws, IIIs y } \\
\text { IIIw }\end{array}$ \\
\hline
\end{tabular}


Tabla 1. Características de las zonas de recarga (cont.).

\begin{tabular}{|c|c|c|c|c|c|}
\hline 4 & $\begin{array}{l}\text { Predominio de } \\
\text { Argialboles y suelos } \\
\text { con alto contenido de } \\
\text { Sodio y/o Sales } \\
\text { Solubles (Nátricos) y } \\
\text { baja presencia de } \\
\text { Argiudoles típicos y } \\
\text { Argiudoles ácuicos }\end{array}$ & $\begin{array}{l}\text { Franco limosa } \\
\text { con interc. de } \\
\text { horizontes de } \\
\text { textura franco } \\
\text { arcillo limosa y } \\
\text { arcillo limosa }\end{array}$ & $\begin{array}{c}\text { Suelos } \\
\text { excesivamente } \\
\text { húmedos, de relieve } \\
\text { llano y poco } \\
\text { permeables }\end{array}$ & $\begin{array}{l}\text { Drenaje interno pobre } \\
\text { asociados con suelos } \\
\text { afectados moderada a } \\
\text { fuertemente por } \\
\text { salinidad y/o } \\
\text { alcalinidad }\end{array}$ & $\begin{array}{c}\text { IIIws, IVws y } \\
\text { IVes }\end{array}$ \\
\hline 5 & $\begin{array}{c}\text { Suelos que } \\
\text { constituyen los } \\
\text { Complejos } \\
\text { Indeterminados, casi } \\
\text { en su totalidad }\end{array}$ & $\begin{array}{l}\text { Franco limosa y } \\
\text { subsuperf. franco } \\
\text { arcillo limosa a } \\
\text { arcillo limosa y } \\
\text { arcillosa }\end{array}$ & $\begin{array}{c}\text { Comprende suelos } \\
\text { que ocupan terrenos } \\
\text { casi llanos, como así } \\
\text { también suelos } \\
\text { ubicados en } \\
\text { pendientes muy } \\
\text { pronunciadas y con } \\
\text { grave erosión laminar } \\
\text { y en surcos }\end{array}$ & $\begin{array}{c}\text { Drenaje interno pobre } \\
\text { o impedido, } \\
\text { fuertemente afectados } \\
\text { por salinidad y/o } \\
\text { alcalinidad }\end{array}$ & $\begin{array}{l}\text { VIws, VIIws, } \\
\text { VIII y VIes }\end{array}$ \\
\hline
\end{tabular}

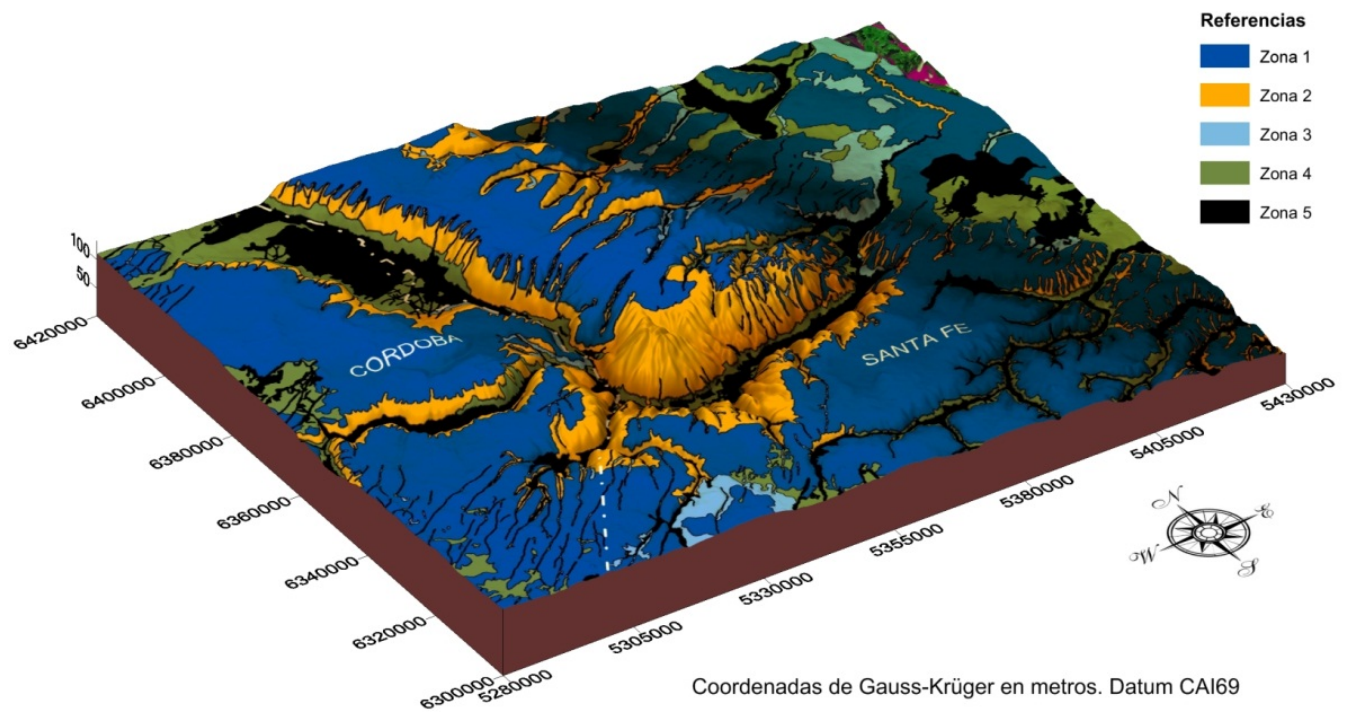

Figura 5. Mapa de recargas superpuesto al modelo digital de elevaciones. Fuente: Polare (2019).

\section{CUANTIFICACIÓN DE LAS RECARGAS}

\section{Datos meteorológicos}

Teniendo como fuentes al Centro de Información Meteorológica del Servicio Meteorológico Nacional (CIM-SMN) y al Instituto Nacional de Tecnología Agropecuaria (INTA), se recopilaron, contrastaron y procesaron, para el período de estudio, los datos meteorológicos diarios (y algunos horarios) de diversas estaciones ubicadas en la zona de estudio y alrededores (Figura 6).

Los datos meteorológicos recopilados corresponden no solo a precipitaciones sino también a diversas variables involucradas en distintos tipos de estudios de evapotranspiración potencial como ser temperaturas máximas y mínimas, temperatura de punto de rocío, humedad relativa, tensión de vapor, velocidad del viento a $2 \mathrm{~m}$ y a $10 \mathrm{~m}$, etc. 


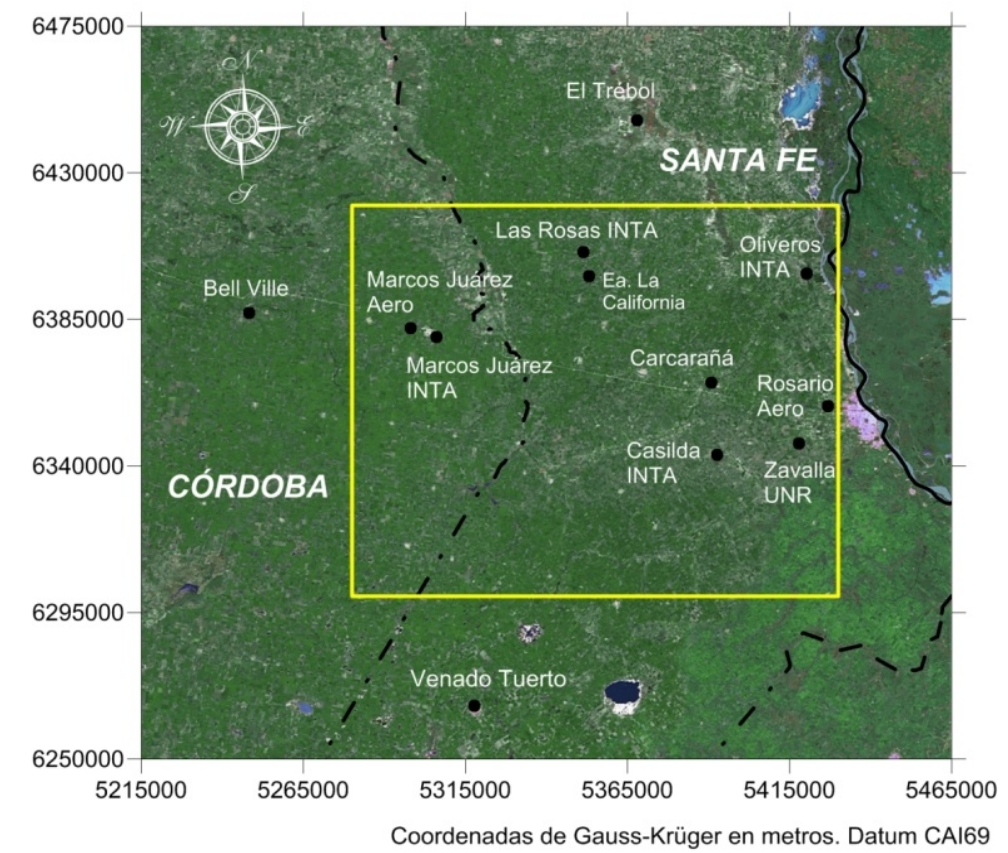

Figura 6. Estaciones meteorológicas empleadas. En línea continua amarilla la zona de estudio. Fuente: Basada en Polare (2019).

Para el presente estudio, por ser las estaciones que presentan las series de datos más completas y por estar además ubicadas en la zona de estudio, se eligieron como las más representativas las de Marcos Juárez, Oliveros y Casilda (con apoyo de la estación UNR Zavalla).

\section{Cálculo de las evapotranspiraciones}

Para el cálculo de las evapotranspiraciones correspondientes a un período de cinco años (01/01/1962 - 31/12/1966) surgió el inconveniente de que la implementación del cálculo de la $\mathrm{ET}_{\mathrm{O}}$ por el método de FAO-56 P-M no fue factible llevarla a cabo en dicho período dada la falta parcial de datos de algunas variables meteorológicas necesarias para el cálculo de la $\mathrm{ET}_{\mathrm{O}}$. La velocidad del viento $\mathrm{u}_{2}$ fue la variable que presentó menor cantidad de datos para el período en cuestión, ya que no se dispuso por casi un año de datos en la localidad de Oliveros, de todo el período en Casilda y de tres meses en Marcos Juárez. En cambio sí se podían desarrollar los cálculos pertinentes de la $\mathrm{ET}_{\mathrm{O}}$ para períodos posteriores al año 1966.

A pesar de ser la velocidad del viento $\mathrm{u}_{2}$ la variable que presenta la menor sensibilidad en la ecuación del método de FAO-56 P-M (Howard y Lloyd, 1979; Gong et al., 2006), para el estudio se optó (en primera instancia) no rellenar los datos faltantes por ningún método estadístico, sino que, apoyado en diversos estudios existentes como los de Xu y Singh (2002), Lu et al. (2005), Yoder et al. (2005), Alexandris et al. (2008), Almorox et al. (2008), Ocampo et al. (2009), Ocampo y Rivas (2010), Sánchez Martínez y Carvacho Bart (2011), Fisher y Pringle III (2013), Tabari et al. (2013), Soriano Soto et al. (2012), entre otros, se llevó a cabo un estudio de diversos métodos de estimación de $\mathrm{ETP}_{\text {y }} \mathrm{ET}_{\mathrm{O}}$ en el período 1970-2009 con el objetivo de elegir aquel que tuviera el mejor ajuste al método de FAO-56 PM y que involucrara la menor cantidad de variables con datos disponibles. Se evaluaron los métodos de Priestley - Taylor (1972), Hargreaves - Samani (1985), Turc (1961) y Thornthwaite (1948).

Se efectuó un trabajo que contempló el cálculo de diversos estadísticos como el coeficiente de eficiencia (E) (Nash y Sutcliffe, 1970) y el coeficiente de determinación $\left(\mathrm{R}^{2}\right)$ a través de análisis de regresión simple de cada método respecto al estándar FAO-56 P-M, como así también el cálculo de los valores totales anuales, el valor promedio anual de $\mathrm{ETP} / \mathrm{ET}_{\mathrm{O}}$, y las diferencias porcentuales respecto al método estándar con la finalidad de evidenciar las variaciones interanuales, entre otras.

Finalmente, el método adoptado fue el de Hargreaves-Samani (H-S) (Ecuación 3), que fue el que mejor ajustó para la década 1970-1979, con valores de $\mathrm{E} \mathrm{y}^{2}$ de 0.97 y 0.98 , respectivamente. 
$\mathrm{ET}_{\mathrm{O}}=0.0023\left(\mathrm{~T}_{\max }-\mathrm{T}_{\min }\right)^{0.5}\left(\mathrm{~T}_{\operatorname{med}}-17.8\right) \mathrm{Ra}$

donde $\operatorname{ET}_{\mathrm{O}}\left(\mathrm{mm} . \mathrm{d}^{-1}\right)$ es la evapotranspiración de referencia, $\mathrm{T}_{\max }$ y $\mathrm{T}_{\min }\left({ }^{\circ} \mathrm{C}\right)$ corresponden a las temperaturas máximas y mínimas diarias, respectivamente, $\mathrm{T}_{\text {med }}\left({ }^{\circ} \mathrm{C}\right)$ es la temperatura media diaria y $\mathrm{Ra}\left(\mathrm{mm} . \mathrm{d}^{-1}\right)$ es la radiación extraterrestre.
En la Figura 7 se muestran los valores de evapotranspiración mensual obtenidos por el método elegido para el período 1962-1966 en las localidades de Oliveros, Casilda y Marcos Juárez, observándose que los máximos valores de evapotranspiración se dan en los meses estivales, mientras que los mínimos en los meses invernales, adoptando un comportamiento periódico en el tiempo.

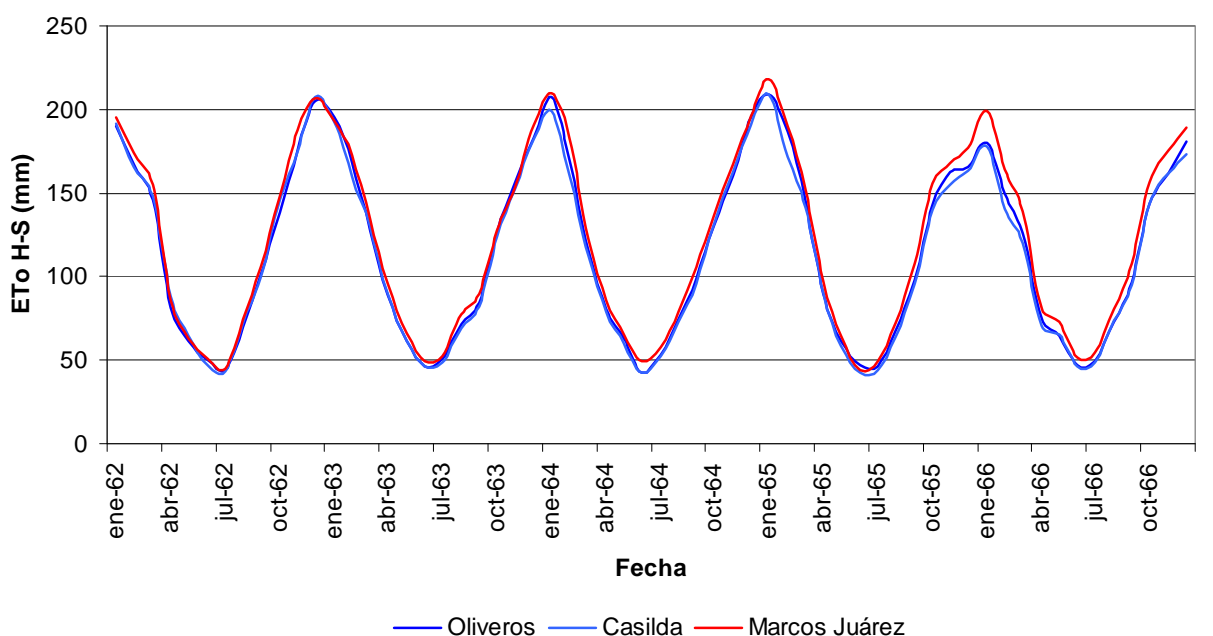

Figura 7. ET $_{\mathrm{O}} \mathrm{H}-\mathrm{S}$ mensuales, período 01/1962 al 12/1966. Fuente: Polare (2019).

Determinación de los balances hídricos en las zonas de recarga

Se observan en la Figura 8 las cinco zonas de recarga definidas en su momento. Dado que las estaciones meteorológicas adoptadas para los estudios de balance hídrico fueron Oliveros, Casilda (ambas en la provincia de Santa Fe) y Marcos Juárez (provincia de Córdoba), se dividió la zona de estudio en áreas de influencia aplicando el método de los polígonos de Thiessen.

De esta manera la zona de estudio quedó dividida en tres Sectores de Estudios de Balance Hídrico (SEBH), donde se emplearon las precipitaciones y evapotranspiraciones potenciales diarias de Oliveros, Casilda y Marcos Juárez, según corresponda.

Para el cálculo de las CAD fue necesario analizar cuáles son las series, asociaciones y complejos de suelos con mayor presencia areal en cada una de los tres SEBH y cómo estaban distribuidos en los mismos. Una vez terminado este análisis, se cruzaron los datos recopilados y se confeccionó en cada SEBH un perfil edáfico representativo para cada una de las zonas de recarga. Los horizontes que conformaron cada uno de los perfiles citados estuvieron definidos por sus espesores, texturas y humedades correspondientes a la CC y PMP. Luego, a través del dato de la profundidad radicular efectiva de los cultivos predominantes en cada zona de recarga, se obtuvieron los valores de la CAD para cada una de ellas.

Posteriormente, y aplicando el método del CN-SCS, se determinaron los Grupos Hidrológicos de Suelos (GHS) a los cuales pertenecían los perfiles edáficos representativos definidos anteriormente, basándose para dicha clasificación en las características texturales de los mismos.

Teniendo en cuenta esto y en función del tipo de cultivos y el uso del suelo, se determinaron los números de curva $\mathrm{CN}_{\text {II }}$ para cada zona de recarga (Luque et al., 1979; USDA-NRCS, 2002, 2004, 2009; Riccardi et al., 2008; Scuderi et al., 2008; Forestieri, et al., 2013).

Una característica importante en la zona 2 de recarga es la presencia de erosión en el suelo debida a que es la zona que presenta el mayor gradiente de pendiente topográfica del área de estudio. 


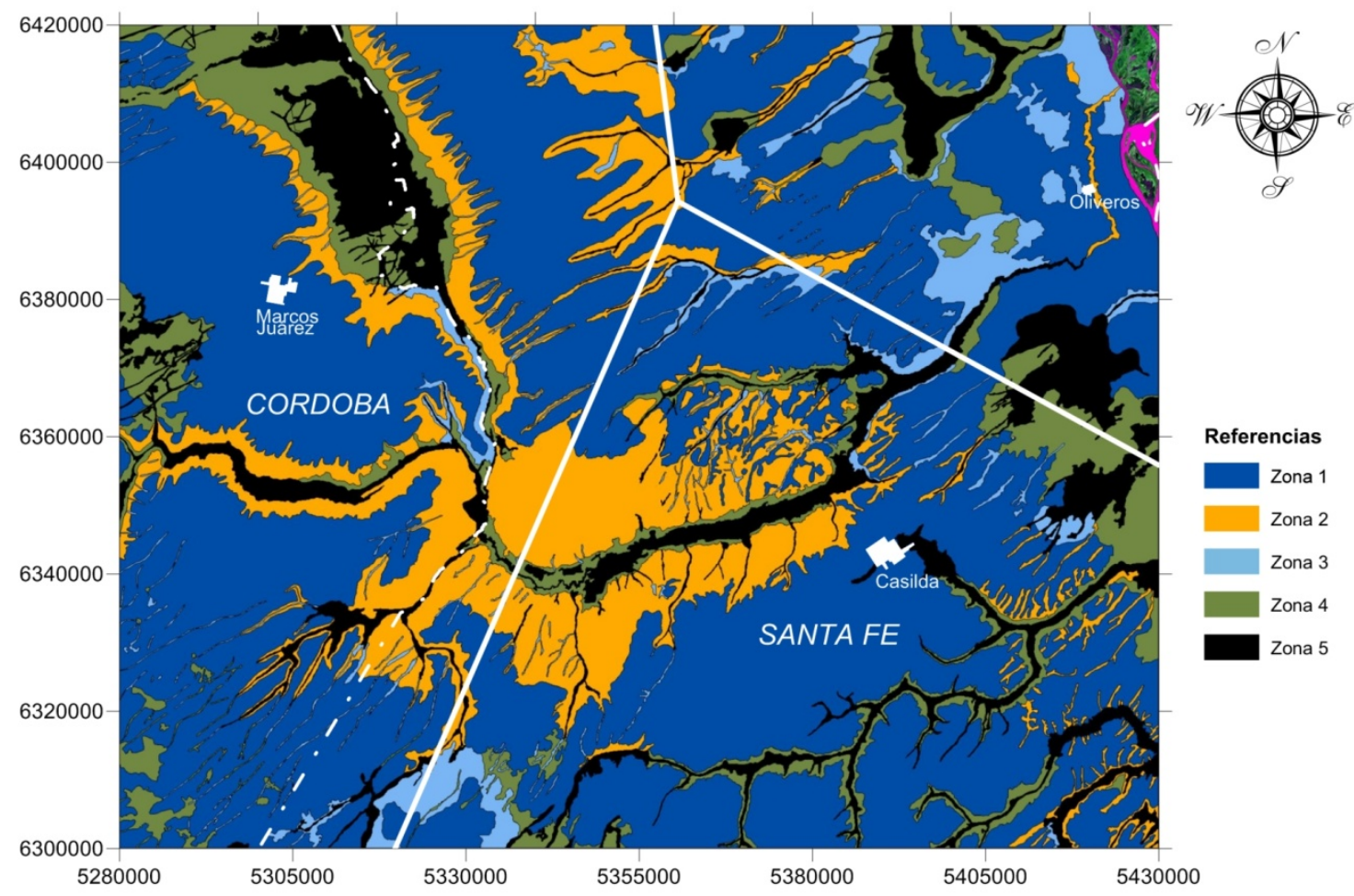

Coordenadas de Gauss-Krüger en metros. Datum CAI69

Figura 8. Zonas de recarga. División de la zona de estudio en tres sectores de acuerdo con qué estación meteorológica se trabaje: Oliveros, Casilda o Marcos Juárez. Fuente: Polare (2019).

A pesar de que la pendiente máxima asumida por el método del SCS para no modificar el CN es del 5\% (Huang et al., 2006; Ritzema, 2006; Hawkins et al., 2009), Luque et al. (1979) consideraron en su trabajo la incidencia de la pendiente en el valor del $\mathrm{CN}_{\mathrm{II}}$, aumentando éste a medida que crece la pendiente topográfica, por lo que se adoptó este criterio para los $\mathrm{CN}_{\mathrm{II}}$ de la zona 2 de recarga, en función del rango de pendiente que adopta la moda en cada una de los SEBH.

A modo de ejemplo, se muestran para el SEBH Casilda los valores de las variables citadas anteriormente de cada una de las cinco zonas de recarga (Tabla 2).

Por último, se efectuaron los balances hídricos seriados para todas las zonas de recarga del área de estudio para el período de tiempo (01/01/1962 a 31/12/1966).

\section{RESULTADOS}

Para el valor de la recarga de cada una de las zonas se adoptó el promedio anual de las recargas obtenidas en el BHS para el período de estudio 1962-1966.

En la Figura 9 se observan, a modo de ejemplo, los valores de recargas y precipitaciones diarios, mensuales y anuales para la zona 1 de recarga en el período de estudio para la SEBH Casilda.

Se observa en el estudio diario que las recargas prácticamente coinciden con eventos de precipitaciones importantes, consecuencia de las lluvias de días previos y las condiciones de humedad en las que se encuentra el suelo al momento de dichos eventos, de acuerdo a la metodología aplicada.

A nivel mensual, si bien se pierde la distribución temporal de las precipitaciones, se mantendría la tendencia antes señalada. En el estudio anual, se observa que la recarga representa un porcentaje bajo respecto a las precipitaciones.

En la Tabla 3 se presentan, para cada zona de recarga, los valores de recarga finales para cada una de las cinco zonas definidas, como así también el porcentaje de la recarga respecto a la precipitación media. 
Cuantificación de la recarga al acuífero en el sector inferior de la cuenca del río Carcarañá

Tabla 2. SEBH Casilda. Variables edáficas y de escurrimiento superficial consideradas para cada zona de recarga.

\begin{tabular}{|c|c|c|c|c|c|c|}
\hline \multicolumn{2}{|c|}{ Variable } & Zona 1 & Zona 2 & Zona 3 & Zona 4 & Zona 5 \\
\hline \multirow{4}{*}{ 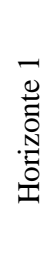 } & textura & FL & FL & FL & FL & FL \\
\hline & espesor (cm) & 20 & 10 & 25 & 30 & 25 \\
\hline & $\mathrm{CC}\left(\mathrm{m} \cdot \mathrm{m}^{-1}\right)$ & 0.37 & 0.36 & 0.38 & 0.35 & 0.35 \\
\hline & $\operatorname{PMP}\left(\mathrm{m} \cdot \mathrm{m}^{-1}\right)$ & 0.18 & 0.18 & 0.20 & 0.16 & 0.16 \\
\hline \multirow{4}{*}{ 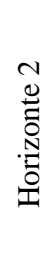 } & Textura & FAL & FAL & AL & FAL-AL & AL-FAL \\
\hline & espesor (cm) & 70 & 60 & 65 & 65 & 70 \\
\hline & $\mathrm{CC}\left(\mathrm{m} \cdot \mathrm{m}^{-1}\right)$ & 0.40 & 0.37 & 0.45 & 0.40 & 0.44 \\
\hline & $\mathrm{PMP}\left(\mathrm{m} \cdot \mathrm{m}^{-1}\right)$ & 0.23 & 0.20 & 0.28 & 0.23 & 0.26 \\
\hline \multicolumn{2}{|c|}{ GHS } & C & $\mathrm{C}$ & D & D & D \\
\hline \multicolumn{2}{|c|}{$\operatorname{Pr}(\mathrm{mm})$} & 700 & 700 & 650 & 650 & 450 \\
\hline \multicolumn{2}{|c|}{ CAD (mm) } & 123 & 120 & 113 & 117 & 84 \\
\hline \multicolumn{2}{|c|}{$\mathrm{CN}_{\mathrm{II}}$} & 72 & 78 & 77 & 80 & 84 \\
\hline
\end{tabular}
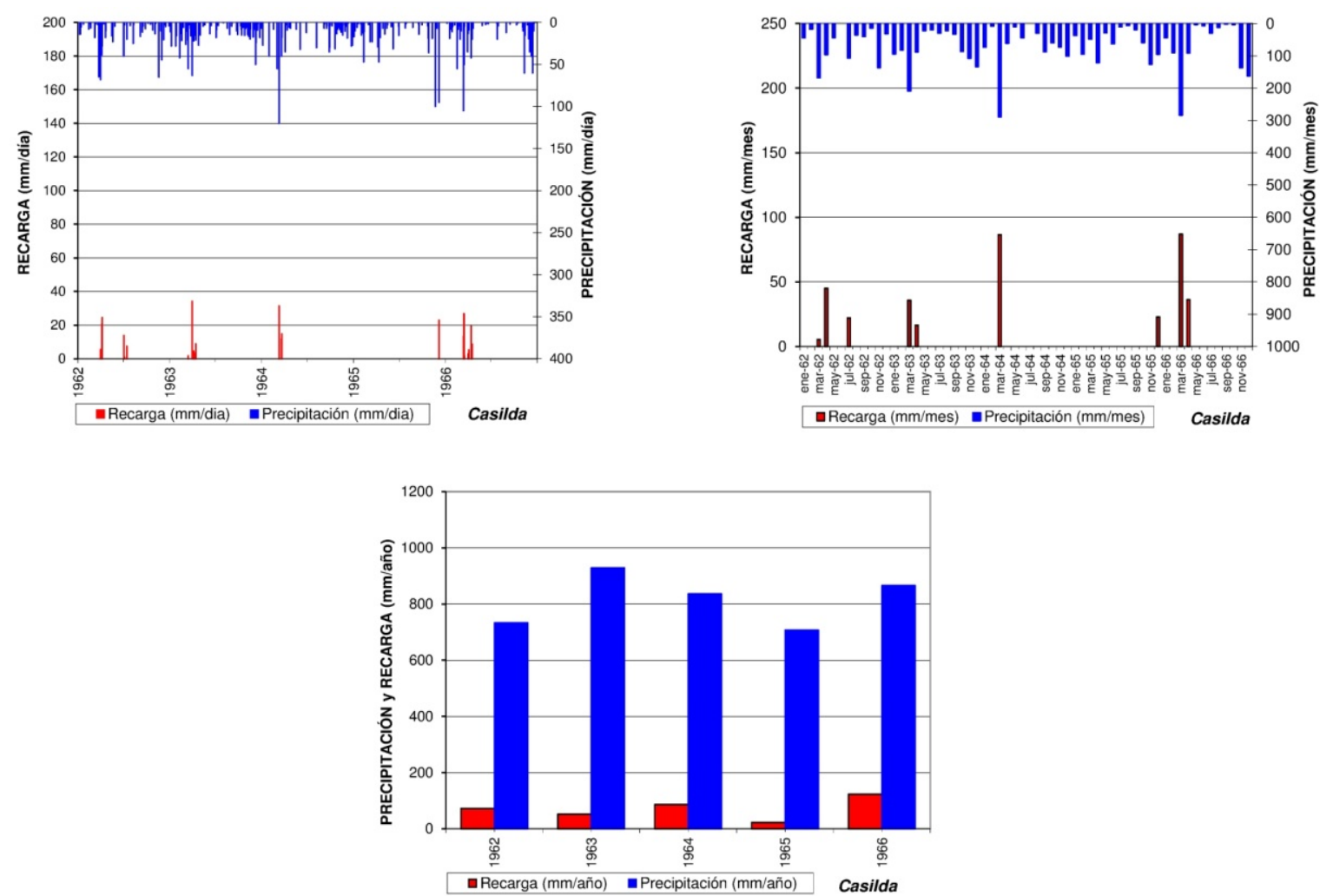

Figura 9. SEBH Casilda. Recargas y precipitaciones diarias, mensuales y anuales (zona 1 de recarga). Basado en Polare (2019). 
Cuantificación de la recarga al acuífero en el sector inferior de la cuenca del río Carcarañá

Tabla 3. Recargas estimadas en $\mathrm{mm}_{\text {.año }}{ }^{-1}$ y porcentaje de la recarga respecto a la precipitación media.

\begin{tabular}{|c|c|c|c|c|c|c|c|c|c|c|}
\hline & \multicolumn{2}{|c|}{ Zona 1} & \multicolumn{2}{|c|}{ Zona 2} & \multicolumn{2}{|c|}{ Zona 3} & \multicolumn{2}{|c|}{ Zona 4} & \multicolumn{2}{|c|}{ Zona 5} \\
\hline Localidad & mm.año-1 & $\%$ & mm.año ${ }^{-1}$ & $\%$ & mm.año-1 & $\%$ & mm.año-1 & $\%$ & mm.año-1 & $\%$ \\
\hline Oliveros & 153.5 & 16.5 & 130.3 & 14.0 & 117.1 & 12.6 & 87.2 & 9.4 & 54.6 & 5.9 \\
\hline Casilda & 71.6 & 8.8 & 58.9 & 7.2 & 53.7 & 6.6 & 31.0 & 3.8 & 20.3 & 2.5 \\
\hline $\begin{array}{l}\text { Marcos } \\
\text { Juárez }\end{array}$ & 46.7 & 6.5 & 42.1 & 5.9 & 38.2 & 5.3 & 17.0 & 2.4 & 5.1 & 0.7 \\
\hline
\end{tabular}

\section{CONCLUSIONES}

Empleando la capacidad de uso de los suelos, haciendo énfasis en aquellos factores relacionados con la dinámica de escurrimiento superficial y subterráneo, se zonificó en detalle la recarga y se desarrolló una herramienta robusta para el cálculo de la misma.

Para el cálculo de las recargas se desarrolló e implementó una planilla de cálculo para los estudios de balance hídrico seriado a paso diario y que contempla las distintas variables involucradas, pudiendo obtener valores de recarga diarios, mensuales y anuales.

Tomado como ejemplo la zona 1 de recarga, es decir, la zona con buen drenaje y sin limitantes, se observan para el período 1962-1966 que las relaciones recarga-precipitación decrecen desde un máximo en el este (Oliveros con 16.5\%) hasta Marcos Juárez en el oeste con 6.5\%, teniendo entre ambas a Casilda con 8.8\%.

\section{AGRADECIMIENTOS}

A los ingenieros agrónomos Jorge Postma (FCEIA-UNR) y Dr. Ing. Sergio Montico (FCAUNR), por el asesoramiento en lo concerniente a la temática edafológica.

\section{REFERENCIAS}

Acutis, M. y Donatelli, M. (2003). SOILPAR 2.00: software to estimate soil hydrological parameters and functions. Short communication. Europ. J. Agronomy, 18, 373-377.

Alexandris, S., Stricevic, R. y Petkovic, S. (2008). Comparative analysis of reference evapotranspiration from the surface of rainfed grass in central Serbia, calculated by six empirical methods against the Penman-Monteith formula. European Water, 21/22, 17-28.

Almorox, J., Hontoria, C. y Benito, M. (2008). Comparación de algunos métodos de estimación de la evapotranspiración en Uruguay. Ingeniería Química Uruguay, 33, 4-9.

Allen, R. G., Pereira, L. S., Raes, D. y Smith, M. (2006). Evapotranspiración del cultivo: Guías para la determinación de los requerimientos de agua de los cultivos. FAO Publicación Serie Riego y Drenaje 56. Roma, Italy: Organización de las Naciones Unidas para la Agricultura y la Alimentación.

Bianchi, A. R. y Cravero, S. A. C. (2010). Atlas Climático Digital de la República Argentina. Estación Experimental Agropecuaria Salta, Centro Regional Salta Jujuy. Salta, Argentina: INTA.

Blarasin, M., Cabrera, A. y Degiovanni, S. (2000). Hidrogeología regional: el agua subterránea como recurso fundamental del sur de la provincia de Córdoba, Argentina. Ponencia presentada en el I Congreso Mundial Integrado de Aguas Subterráneas, XI de la Asociación Brasilera de Aguas Subterráneas (ABAS) y V de la Asociación Latinoamericana de Hidrología Subterránea para el desarrollo (ALHSUD). Fortaleza, Brasil.

Cravero, S. A. C, Bianchi, C. L., Elena, H. J. y Bianchi, A. R. (2017). Clima de la Argentina Mapas digitales mensuales de precipitaciones y precipitación menos evapotranspiración potencial: adenda del Atlas Climático digital de la República Argentina. Salta: INTA.

Fisher, D. K. y Pringle III, H. C. (2013). Evaluation of alternative methods for estimating reference evapotranspiration. Agricultural Sciences, 4(8A), 51-60.

Forestieri, C., Navarro, R., Ruggeri, P., Martín, S., Salama, V. y Policardo, G. (2013). Implementación de medidas no estructurales en la cuenca del arroyo Ludueña - Ley 13.246. Ponencia presentada en el XXIV Congreso Nacional del Agua, San Juan, Argentina.

GeoINTA. (2013). Suelos de la República Argentina. Escala: 1:500 000. Visor GeoINTA. Disponible en: http://visor.geointa.inta.gob.ar/ 
Gong, L., Xu, C., Chen , D., Halldin , S. y Chen, Y. D. (2006). Sensitivity of the Penman-Monteith reference evapotranspiration to key climatic variables in the Changjiang (Yangtze River) basin. Journal of Hydrology, 329, 620-629.

Hargreaves, G. H. y Samani, Z. A. (1985). Reference crop evapotranspiration from temperature. Applied Eng. in Agric., 1(2), 96-99.

Hawkins, R. H., Ward, T. J., Woodward, D. E. y Van Mullem, J. A. (2009). Curve Number Hydrology: State of the Practice. Reston, VA: American Society of Civil Engineers.

Howard, K. W. F. y Lloyd, J. W. (1979). The sensitivity of parameters in the Penman evaporation equations and direct recharge balance. Journal of Hydrology, 41, 329-344.

Huang, M., Gallichand, J., Wang, Z. y Goulet, M. (2006). A modification to the Soil Conservation Service curve number method for steep slopes in the Loess Plateau of China. Hydrol. Process, 20, 579-589.

INTA-MAG. (1981). Mapa de suelos de la Provincia de Santa Fe. Instituto Nacional de Tecnología Agropecuaria (Tomo 1). Rafaela y Castelar: Autores.

INTA. (1974-1988). Colección: Cartas de Suelos de la República Argentina. Escala 1:50000. Buenos Aires, Rafaela y Córdoba: Autor.

INTA. (1990). Atlas de Suelos de la República Argentina escala 1:500000 y 1:1000000. Buenos Aires: Autor.

INTA-Aeroterra SA. (1995). Atlas de Suelos de la República Argentina. [CD Rom]. Buenos Aires: Fundación ArgenINTA.

Kottek, M., Grieser, J., Beck, C., Rudolf, B. y Rubel, F. (2006). World Map of Köppen-Geiger Climate Classification updated. Meteorologische Zeitschrift,15 (3), 259-263.

Lu, J., Sun, G., McNulty, S. y Amatya, D. M. (2005). A Comparison of Six Potential Evapotranspiration Methods for Regional Use in the Southeastern United States. Journal of the American Water Resources Association (JAWRA), 41(3), 621-633.

Luque, J. A., Paoloni, J. D. y Bonorino, G. A. (1979). Estudio Hidrológico e hidrogeológico de la cuenca del río Sauce Grande. Serie Hidrológica $\mathrm{N}^{\circ}$ 3. Departamento de Ciencias Agrarias y Departamento de Ciencias Naturales. Universidad Nacional del Sur. 64 pp.

Nash, J.E. and Sutcliffe, J.V. (1970). River Flor Forecasting through Conceptual Model. Part 1-A Discussion of Principles. Journal of hydrology, 10: 282-290.
Ocampo, D., Rivas, R. y Schirmbeck, J. (2009). Aptitud de diferentes métodos de estimación de la evapotranspiración: aplicación en una zona de clima templado. Aportes de la Hidrología al conocimiento de los recursos hídricos. Ponencia presentada en el VI Congreso Argentino de Hidrogeología, Santa Rosa, La Pampa, Argentina.

Ocampo, D. y Rivas, R. (2010). Comparación de métodos de estimación de la evapotranspiración a escala local en zonas de clima húmedo y árido. Ponencia presentada en el I Congreso Internacional de Hidrología de Llanuras. Azul, Buenos Aires, Argentina.

Penman, H. L. (1948). Natural evaporation from open water, bare soil and grass. Proceedings of the Royal Society of London. Series A, Mathematical and Physical Sciences, 193(1032), 120-145.

Polare, M. H. (2019). Comportamiento del sistema acuífero en la cuenca inferior del río Carcarañá. Provincias de Santa Fe y Córdoba, República Argentina. Tesis de Maestría. Facultad de Ciencias Exactas, Ingeniería y Agrimensura, Universidad Nacional de Rosario, Rosario, Argentina.

Priestley, C. H. y Taylor, R. J. (1972). On the Assessment of Surface Heat Flux and Evaporation Using Large-Scale Parameters. Monthly Weather Review, 100, 81-92.

Rawls, W.J., Brakensiek, D.L., and Saxton, K.E. (1982). Estimation of soil water properties.Trans. ASAE 25:1316-1320.

Riccardi, G., Zimmermann, E., Basile, P., Stenta, H., Scuderi, C., García, M. y Rentería, J. (2008). El modelado de escurrimiento superficial en cuencas del sur de la provincia de Santa Fe. En G. Riccardi, P. Basile, E. Zimmermann, H. Stenta, C. Scuderi, J. Rentería, y M. García (Eds.), Modelación de procesos hidrológicos asociados al escurrimiento superficial en áreas de llanura (pp. 3-20). Rosario: UNR Editora.

Ritzema, H. P. (2006). Drainage Principles and Applications. Publication $16 \quad$ (3 ${ }^{\mathrm{a}} \quad$ Ed.). Wageningen: ILRI (International Institute for Land Reclamation and Improvement).

Rohli, R. V. y Anthony J. Vega, A. J. (2015). Climatology ( $3^{\mathrm{a}}$ Ed.). Burlington, MA: Jones \& Bartlett Learning.

Rubel, F., y Kottek, M. (2010). Observed and projected climate shifts 1901-2100 depicted by world maps of the Köppen-Geiger climate classification. Meteorologische Zeitschrift, 19(2), 135-141.

Sánchez Martínez, M. y Carvacho Bart, L. (2011). Comparación de ecuaciones empíricas para el cálculo de la evapotranspiración de referencia en la 
Región del Libertador General Bernardo O’Higgins, Chile. Revista de Geografía Norte Grande, 50, 171-186.

Scuderi, C., Stenta, H., Riccardi, G., Zimmermann, E., Basile, P., García, M. y Rentería, J. (2008). Uso de imágenes satelitales y SIG en la generación de mapas de CN y evaluación de la agregación espacial de este parámetro mediante modelación. En G. Riccardi, P. Basile, E. Zimmermann, H. Stenta, C. Scuderi, J. Rentería, y M. García (Eds.), Modelación de procesos hidrológicos asociados al escurrimiento superficial en áreas de llanura (pp. 77-95). Rosario: UNR Editora.

Scozzafava, M. y Tallini, M. (2001). Net Infiltration in the Gran Sasso Massif of central Italy using the Thornthwaite water budget and curve-number method. Hydrogeology Journal, 9(5), 461-475.

Soriano Soto, M. D., Pons Marti, V., García-España Soriano, L. y Llinares Palacios, J. (2012). Comparación de los valores obtenidos en zonas contrastadas climáticamente en la península ibérica utilizando diferentes modelos para el cálculo de la evapotranspiración. En Asociación Española de Climatología (Ed.), Ponencia presentada en el VIII Congreso Internacional “Cambio Climático. Extremos e impactos” (pp. 651-658), Salamanca, España.

Tabari, H, Grismer, M. E. and Trajkovic, S. (2013). Comparative analysis of 31 reference evapotranspiration methods under humid conditions. Irrig. Sci. 31, 107-117.

Thornthwaite, C. W. (1948) An Approach toward a Rational Classification of Climate. Geographical Review, 38(1),55-94.

Thornthwaite, C. W. y Mather, J. R. (1957). Instructions and tables for computing potential evapotranspiration and the water balance. Publ. Climatol., 10(3), 1-127.

Turc, L. (1961) Water requirements assessment of irrigation, potential evapotranspiration: Simplified and updated climatic formula. Annales Agronomiques, 12, 13-49.

USDA-NRCS. (2002). Chapter 8: Land Use and Treatment Classes. In USDA-NRCS, National Engineering Handbook, title 210-VI. Part 630 Hydrology. Washington, DC: Authors.

USDA-NRCS. (2004). Chapter 9: Hydrologic SoilCover Complexes. In USDA-NRCS, National Engineering Handbook, title 210-VI. Part 630 Hydrology. Washington, DC: Authors.

USDA-NRCS. (2009). Chapter 7: Hydrologic Soil Groups. In USDA-NRCS, National Engineering
Handbook, title 210-VI. Part 630 Hydrology. Washington, DC: Authors.

Venencio, M. del V. (2007). La Recarga Natural al Acuífero Libre y su Vinculación con la Variabilidad Climática Regional. Tesis Doctoral. Facultad de Ciencias Exactas, Físicas y Naturales, Universidad Nacional de Córdoba, Córdoba, Argentina.

Westenbroek, S. M., Kelson, V. A., Dripps, W. R., Hunt, R. J. y Bradbury, K. R. (2010). SWB A modified Thornthwaite Soil Water Balance code for estimating ground-water recharge. (USGS Techniques and Methods 6-A31). Reston, VA: USGS.

Woodward, D. E., Hawkins, R. H., Jiang, R., Hjelmfelt, A.T., y Van Mullem, J. A. (2003). Runoff Curve Number method - Examination of the initial abstraction ratio. En ASCE (Ed.), Ponencia presentada en el World Water and Environmental Resources Congress 2003, Philadelphia, USA.

Xu, C. Y. y Singh, V. P. (2002). Cross Comparison of Empirical Equations for Calculating Potential Evapotranspiration with Data from Switzerland. Water Resources Management, 16(3), 197-219.

Yoder, R. E., Odhiambo, L. O. y Wright, W. C. (2005). Evaluation of methods for estimating daily reference crop evapotranspiration at a site in the humid southeast United States. Applied Engineering in Agriculture, 21(2), 197-202.

Tipo de Publicación: ARTíCULO.

Trabajo recibido el 25/09/2021 y aprobado para su publicación el 18/11/2021.

\section{COMO CITAR}

Polare, M. H. y Vives, L. S. (2021). Cuantificación de la recarga al acuífero en el sector inferior de la cuenca el Río Carcarañá. Cuadernos del CURIHAM. 27, 69-84. DOI: https://doi.org/10.35305/curiham.v27i.171

Este es un artículo de acceso abierto bajo licencia: Creative Commons Atribución - No Comercial Compartir Igual 4.0 Internacional (CC BY-NC-SA 4.0) (https://creativecommons.org/licenses/by-ncsa/4.0/deed.es). 